\title{
Signo de la cabeza de Medusa
}

\section{Caput Medusae Sign}

\author{
Cintia Edith Capristo ${ }^{1}$ Pablo Sebastián Sauré ${ }^{1}$ Estefanía Reyna ${ }^{1}$
}

${ }^{1}$ Hospital Interzonal General de Agudos General José de San Martín, La Plata, Buenos Aires, Argentina

Rev Argent Radiol 2020;84:39-41.

El signo de la cabeza de Medusa corresponde a un hallazgo imagenológico observable en las anomalías venosas del desarrollo (AVD), antes conocidas como angiomas venosos, tanto en tomografía computada (TC) como en resonancia magnética (RM) con contraste endovenoso. Consiste en un ramillete de venas medulares dilatadas que se disponen radialmente alrededor de una vena colectora central, la cual drena al sistema venoso superficial, a una vena ependimaria profunda $o$ a un seno venoso. ${ }^{1-3}$ El signo fue descripto por primera vez angiográficamente en 1967 por Wolf en un paciente con angiomas venosos múltiples, mientras que el primer registro radiológico fue realizado en 1968 por Constans. ${ }^{4}$ Su nombre proviene de la mitología griega, haciendo referencia a las serpientes que forman el cabello de Medusa, un monstruo que convertía en piedra a aquellos que la miraran fijamente a los ojos (-Figura $\mathbf{1}$ ).
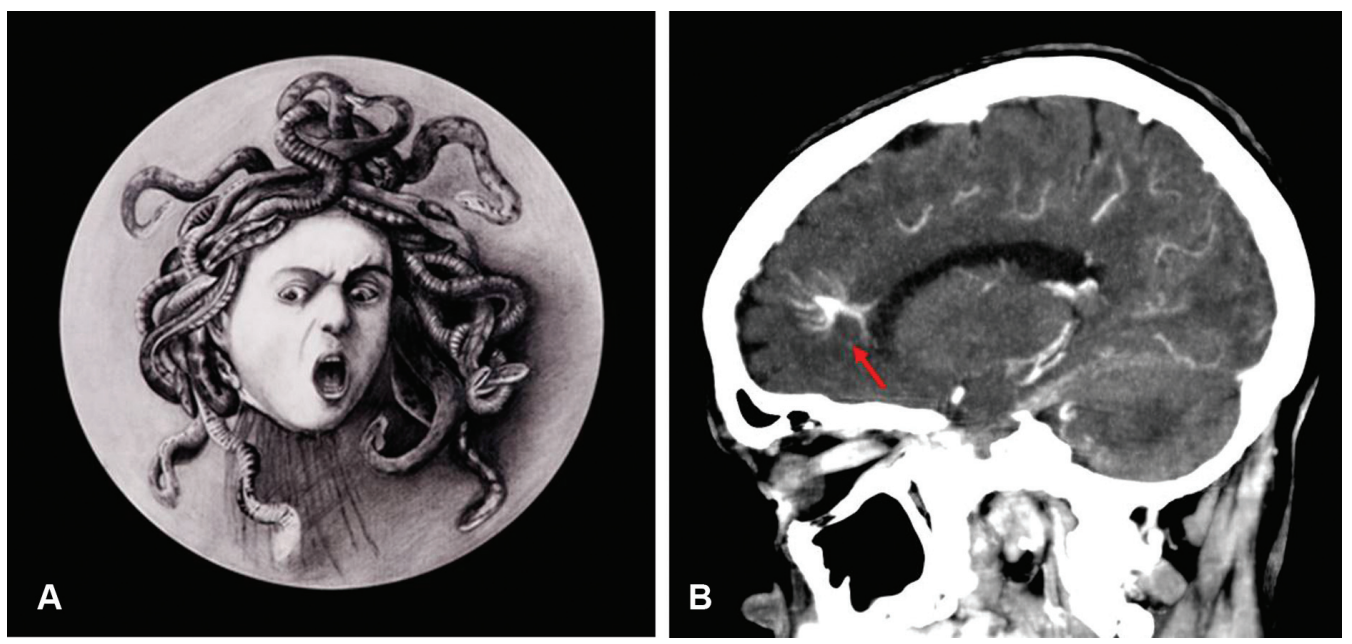

Fig. 1 (A) Imagen de Medusa, divinidad de la mitología griega. (B) Corte sagital de TC con contraste, donde se evidencia el signo de la cabeza de Medusa (flecha roja).

received

December 5, 2018

accepted

February 18, 2020
Address for correspondence Capristo Cintia,

(e-mail: cintiacapristo@hotmail.com).

La patogenia de las AVD no está del todo clara. Su origen podría asociarse a la ausencia de la vía normal de drenaje venoso de un territorio del cerebro (por ejemplo la hipoplasia o agenesia del 1/3 anterior del seno longitudinal superior) (-Figura 2). ${ }^{4}$

Para algunos autores, las AVD representan la persistencia en la edad adulta de un drenaje venoso embrionario, siendo por tanto variantes de la normalidad. Las venas tienen escaso componente de músculo liso y tejido elástico con parénquima cerebral sano entre ellas, no habiendo componente arterial en esta entidad. ${ }^{3,4}$

Por lo antes mencionado, representarían una variante anatómica fisiológicamente competente de las vías de drenaje venoso de una región del cerebro con funcionalidad normal. ${ }^{4,5}$

Son más frecuentes en las regiones irrigadas por la arteria cerebral media y en el territorio de la vena de Galeno, y pueden estar asociados a una malformación cavernosa en un $30 \%$ de los casos. No son hereditarios. ${ }^{2,3}$ 

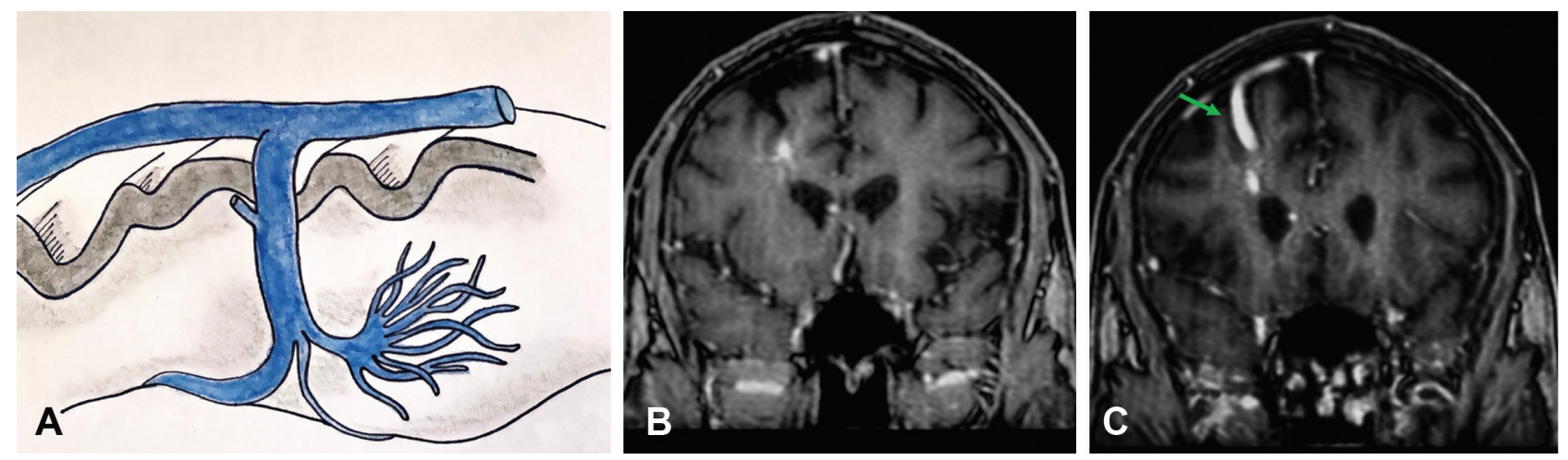

Fig. 2 (A) Dibujo esquemático que demuestra a las venas de disposición radial a lo largo de la pared del ventrículo lateral con drenaje en una vena cortical dilatada. (B) Corte coronal de secuencia ponderada en T1 con contraste. Confluencia de las venas medulares dispuestas radialmente alrededor de una vena colectora central. (C) Mismo paciente evidenciándose vena de drenaje cortical dilatada (flecha verde).

\section{Hallazgos imagenológicos}

El Signo de la cabeza de Medusa puede observarse tanto en la TC como en la RM cuando se administra el contraste. La TC sin contraste endovenoso habitualmente es normal. Luego de administrar el contraste, pueden observarse focos lineales o puntiformes de realce que convergen a una única vena tubular de drenaje dilatada. Esta última se puede ver en varios cortes consecutivos o en toda su extensión, dependiendo de su trayecto. ${ }^{1,5}$

En la RM sin contraste endovenoso pueden pasar desapercibidos, evidenciándose únicamente la vena central dilatada como un vacío de flujo lineal. Las secuencias ponderadas en T2 pueden mostrar alta intensidad de señal debido al flujo lento de tipo venoso, que no debe confundirse con trombosis. Con frecuencia, en estas secuencias se observa una línea paralela de alta señal rodeando la vena colectora, que probablemente corresponda a un espacio perivascular con LCR. Con la administración del contraste realza intensamente y puede apreciarse la imagen típica en cabeza de Medusa. ${ }^{5}$ Adicionalmente, las imágenes de susceptibilidad magnética (SWI, por su sigla en inglés), como el T2*, pueden mostrar focos hipointensos si se asocian a hemorragia o a malformación cavernosa (-Figura 3$)^{1,5}$

Angiográficamente, la imagen es característica, con una fase arterial normal o con discreta captación en fase capilar tardía, haciéndose realmente evidente en la fase venosa ( Figura 4). ${ }^{1,5}$

Las AVD constituyen la malformación cerebrovascular más frecuente, representando el $63 \%$ de las malformaciones vasculares en un estudio de autopsias, con una incidencia global de $2 \%{ }^{1}$

La mayoría son solitarias y están ubicadas en los lóbulos frontales, pero pueden aparecer en cualquier lugar del encéfalo, incluso en fosa posterior. Normalmente, se localizan en la región paraventricular, pudiendo también ser subcorticales y yuxtacorticales.

Se consideran clínicamente silentes, descubiertas incidentalmente en estudios de imágenes, aunque hay
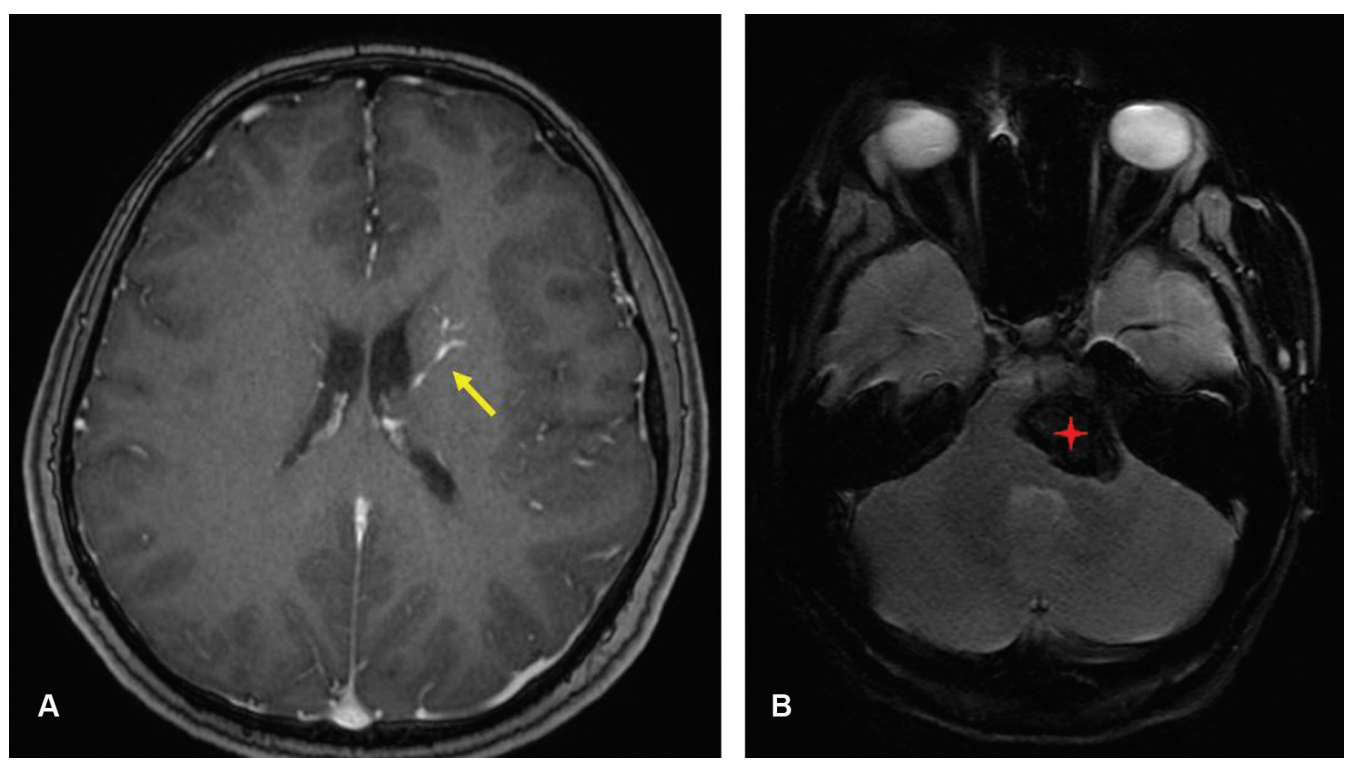

Fig. 3 (A) Secuencia ponderada T1 con contraste con una AVD izquierda que drena a una vena ependimaria (flecha amarilla). (B) Cavernoma de tronco en el mismo paciente visualizado en secuencia EPI GRE (estrella). 


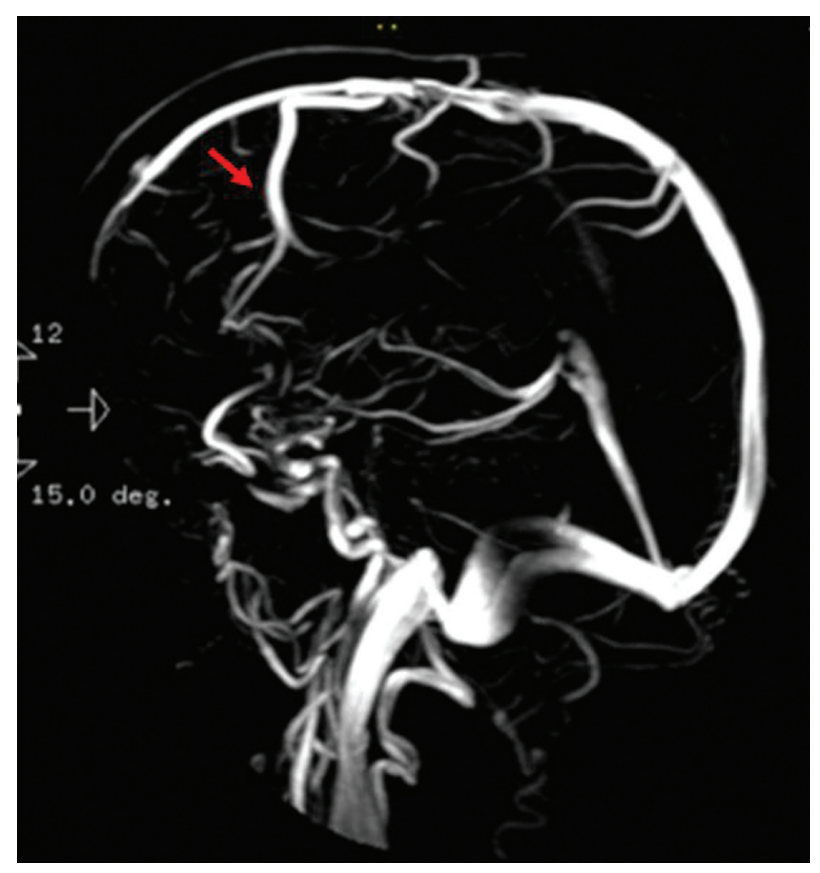

Fig. 4 AngioRM venosa del paciente de la - Figura 2, que demuestra la AVD frontal derecha.

controversias acerca de su posible asociación con hemorragias, principalmente cuando están asociadas a un angioma cavernoso o están situadas en la fosa posterior. ${ }^{1,2,5}$

Un aspecto importante de esta lesión es que la AVD representa una vía compensatoria de drenaje para el cerebro normal. El sacrificio de esta vía puede producir un infarto venoso del tejido cerebral que drena la misma. Por lo tanto, cabe recalcar que no constituyen lesiones quirúrgicas, a menos que se establezca un diagnóstico equivocado, debiendo realizarse una evaluación minuciosa y muy crítica de los síntomas neurológicos antes de atribuirlos a esta entidad. ${ }^{5}$

Los principales diagnósticos diferenciales se plantean con malformaciones arteriovenosas, neoplasias hipervasculares, telangiectasias capilares, enfermedad desmielinizante, ictus hemorrágico, síndrome de Sturge Weber y oclusión del seno dural. $^{1,2}$

\section{Conclusión}

Dada la alta prevalencia de las AVD en estudios por imágenes, resulta importante identificar el signo descripto en esta revisión, ya que permite su diagnóstico, el cual suele ser incidental y no conlleva tratamiento.

\section{Responsabilidades éticas}

Protección de personas y animales. Los autores declaran que para esta investigación no se han realizado experimentos en seres humanos ni en animales.

Confidencialidad de los datos. Los autores declaran que han seguido los protocolos de su centro de trabajo sobre la publicación de datos de pacientes.

Derecho a la privacidad y consentimiento informado. Los autores declaran que en este artículo no aparecen datos de pacientes.

Conflicto de intereses

Los autores declaran no tener ningún conflicto de intereses.

\section{Agradecimientos}

Dra. Jimena Mariano

\section{Bibliografía}

1 Atlas WS, Do HM. Intracranial Vascular Malformations and Aneurysms. In: Scott W. Atlas. Magnetic Resonance Imaging of the Brain and Spine. 4th ed. Lippincott Williams \& Wilkins; 2009: 738-742

2 Córdoba Rovira A, Samitier Pastor E, Salvadó Geli A, Ramos Gadea A, Tarragona ES. Signos neuroradiológicos clásicos en TC y RM craneal. SERAM 2014(S-0906):

3 Abarca-Olivas J, Botella-Asunción C, Concepción-Aramendía LA, Cortés-Vela JJ, Gallego-León JI, Ballenilla-Marco F. Hemorragia intracerebral secundaria a trombosis espontánea de una anomalíavenosa del desarrollo: 2 casos y revisión de la literatura. Neurocirugia. 2009;20(03):265-271

4 Sánchez Medina Y, Pérez del Rosario PA, Domínguez J, Millán A. Angioma venoso asociado a hemorragia cerebelosa. Presentación de un caso. Neurocirugia. 2013;24(02):88-92

5 Lee M, Kim MS. Image findings in brain developmental venous anomalies. J Cerebrovasc Endovasc Neurosurg. 2012;14(01):37-43 